\title{
ANÁLISIS FENOMENOLÓGICO DEL TROPO PASAR A LLEVAR
}

\author{
PHENOMENOLOGICAL ANALYSIS OF THE TROPE PASAR A \\ LLEVAR (TOUCH, DRAG, PUSH, ETC. ACCIDENTALLY)
}

\section{SYLVIA CONTRERAS SALINAS* MÓNICA RAMİREZ PAVELIC**}

\section{RESUMEN}

Este artículo da cuenta de los hallazgos de una investigación etnográfica cuyo objetivo era apreciar algunos tropos definitorios de las preocupaciones existenciales que se construyen en la vida cotidiana de una familia que habita una zona rururbanizada. Desde aquí profundizamos en el tropo pasar a llevar que resultó ser un parámetro de investigación muy fecundo a la hora de ilustrar diversos aspectos, especialmente el de la fenomenología de la desigualdad y de la exclusión, desde su uso como dato incuestionable en la serie de argumentaciones que se desvelan en sus narrativas, conformando un saber que se configura en diversas prácticas.

Palabras clave: Saberes locales, existencia, tropología, fenomenología.

\section{ABSTRACT}

This article reports the findings of an ethnographic study whose objective was to appreciate some defining tropes of the existential concerns that are constructed in everyday life of a family that inhabits an urbanised rural area. From here we delve into the trope pasar a llevar which proved a very fruitful research parameter when illustrating various aspects, especially the phenomenology of inequality and exclusion, from its use

* Doctora en Pedagogía de la Diversidad Sociocultural. Facultad de Humanidades, Departamento de Educación, Universidad de Santiago de Chile. Santiago, Chile. Correo electrónico: sylvia.contreras.s@usach.cl

** Doctora en Psicología. Universidad Arturo Prat. Iquique, Chile. Correo electrónico: trapecio@gmail.com 
as unquestionable data in the series of arguments that are revealed in their narratives, building knowledge that is configured in various practices.

Keywords: Local knowledge, existence, anthropology, phenomenology.

Recibido: 26.09.16. Aceptado: 22.11.16.

\section{ASPECTOS INTRODUCTORIOS}

\section{Diálogo de saberes}

$\mathrm{E}$

L DIÁLOGO DE SABERES constituye un fenómeno que poco a poco se ha ido posicionando en los análisis, especialmente en el marco de la vida cotidiana y sus saberes. Saberes que, en opinión de muchos, han sido relegados a un plano inferior o en el mejor de los casos se les ha restringido a aquellos gestados en torno a las actividades de cultivo de la tierra, de manufactura (artesanía) o relacionadas con las prácticas de salud (hierbas medicinales), además de otras prácticas. De esta manera, la riqueza de los saberes que se conforman en la vida cotidiana es frecuentemente omitida y considerados estos, la mayoría de las veces, como receptores pasivos de los conocimientos generados en instituciones y espacios legitimados para ello.

En este marco, apreciamos la pertinencia de promover la visibilización de los saberes vinculados a la cotidianeidad, a los haceres/saberes de seres humanos situados y encarnados, siendo este uno de los aspectos más álgidos, pues persisten las conformaciones de poder-saber en este desafío. Persistencia que se observa en las múltiples denominaciones de dichos saberes, donde cada una de ellas marca distintos énfasis, presencias y ausencias (Sabiduría popular: Chamorro, 1983; Ciencia indígena: Cardona, 1986; Conocimiento campesino, Toledo, 1994; Sistemas de saberes indígenas y campesinos: Argueta, 1997; Saberes locales: Leff, Argueta, Boege y Porto, 2002; Conocimiento popular y Ciencia del pueblo: Fals Borda, 1981, 1987; Epistemologías locales: Descola y Palsson, 2001) (Argueta, 2011; Contreras \& Ramírez, 2013).

Asimismo, se aprecian tensiones en los esfuerzos por caracterizarlos, por cómo se estructuran y por cómo desvelar sus atributos y sus formas de reproducción, transmisión y/o distribución. Además de la interrogante sobre qué hacer frente a la pluralidad de saberes, ¿validarlos en sus propios principios y re-establecer sus derechos? Pero ¿quién lo hace?, ¿la ciencia occidental, las instituciones legitimadas para ello? A este respecto, Argueta (2011) se pregunta: 
¿Son, como se discutió mucho tiempo, saberes de carácter meramente práctico con ausencia de motivaciones intelectuales o hay ahí indagaciones realizadas bajo la misma curiosidad intelectual que motiva a un científico? ¿Los saberes locales están sumergidos en las cosmovisiones, y por lo tanto imbuidos de religiosidad solamente o hay también saberes y técnicas secularizadas? (p. 18).

Entre las posibles respuestas encontramos las relaciones y tramas que sujetan al ser humano a una especie de "solidaridad", a un "conocimientore-conocimiento" (De Sousa Santos, 2003), posicionando al otro/a y lo Otro en la categoría de alteridad radical. Convirtiendo el saber en indagación, en elucidación y esclarecimiento de palabras borradas, adentrándonos en una sociología del silencio y en una teoría de la traducción para hacer conmensurables los distintos saberes (De Sousa Santos, 2003).

Atendiendo a que la visibilización de los saberes no debería ser entendida como una misión de rescate fundamentalista o esencialista por la autenticidad cultural, el punto es, más bien, situar la diferencia colonial en el centro del proceso, proponiéndose avanzar en una actitud y praxis cómplice, subversiva al sistema, es decir, en una resistencia semiótica capaz de re-significar las formas hegemónicas de saber desde el punto de vista de la racionalidad subalternizada (Mignolo, 2010, p. 231).

\section{SABERES EN TORNO AL DESPLIEGUE DEL DEVENIR HUMANO}

Explorar el despliegue del devenir humano sobre las coordenadas de su existencia no busca responder a la interrogante sobre la esencia del ser humano, de eso ya hay bastantes intentos que se han limitado a las reflexiones y problemáticas de ciertos pensadores, mismos que no han prestado atención a las cavilaciones que se generan en el mundo de la vida cotidiana, en los lenguajes, en la práctica hermenéutica y de-constructiva de seres en un mundo concreto; en consecuencia se han instalado procesos de distribución que han implicado que "quien habla por el otro, controla las formas de habla del otro" (Tadeu da Silva, 1999, pp. 33-34).

Así, el ser no puede re-velarse asumiendo las formas de un ser que ya es, una esencia, puesto que sus modos se des-velan en una irreductible y provisoria anterioridad, es decir, "lo anticipan y desploman sobre él toda su solidez y lo atraviesan" (Foucault, 1968, p. 305). Por otra parte, el saber se gesta en la condición contingente y vulnerable del ser, siendo inherente a este saber la necesidad de afirmar su propia visión del asunto, puesto que 
en "la finitud del hombre, anunciada en la positividad, se perfila la forma paradójica de lo indefinido" (Foucault, 1968, p. 306).

La apuesta en este sentido es de-velar las preocupaciones existenciales como una forma de contribuir a un humanismo radical. Preocupaciones que desbordan la relación del ser humano consigo mismo. Postulando que cada ser es el único testigo de su existencia, encontrando la posibilidad de un ser inesperado, que se halla en las paradojas del cuerpo, de las cosas, del otro y, sobre todo, del tiempo. Un ser encarnado.

Desde aquí, el saber se gesta en la cotidianidad y demanda ser legitimado y entrar a dialogar con el Otro y lo Otro, desprendiéndose que le compete un diálogo de saberes en el marco de las preocupaciones existenciales, por el hecho de re-conocer y des-ocultar las singulares y particulares interpretaciones y tipificaciones en que ha caído cada fenómeno existencial, en y desde la cotidianidad.

\section{SABERES GESTADOS EN ESCENARIOS ADVERSOS}

Al proponernos desvelar saberes gestados en escenarios desvalorizados, debemos tener en cuenta que iremos al encuentro de discursos o relatos que se conforman en aspectos heredados de un determinado contexto, por ejemplo, se aprecia que los modos existenciales de los habitantes del mundo rural se configuran en la necesidad de no ser explotados, recurriendo a las mismas herramientas que usan los explotadores, formándose en lo mismo que rechazan. Estas aseveraciones no son formuladas en el vacío; basta poner atención a los discursos que circulan en el medio rural, los cuales están inundados de tropos que lo sintetizan y concretan: "que no te pasen a llevar"; "agrandarse para no ser menos"; "hay que ser otro"; "estudiar pa' mandar al más chico" "llegar a ser alguien", "que sea más que yo", etc. (Contreras, 2013).

Desde lo mencionado anteriormente y en torno a un abordaje de los saberes, la materialidad abrumadora del campesino-laborante-peón-inquilino debe ser pensada y nombrada desde y en los modos existenciales que se configuran en los mundos cotidianos constituidos en sus respectivos entornos. Moradores de una singular finitud, re-crean formas singulares de hacerse humanos, algunos de los cuales se configuran desde unas narrativas que son difícil de des-habitar.

Desde aquí, ellos habitarían lenguajes opacos que proyectan la infinitud de las condiciones y sus formas de ser, frente a una humanización que, por el contrario, alude a la finitud de las limitaciones que entregan la posibilidad de encumbrarla. 


\section{ASPECTOS METODOLÓGICOS}

Los hallazgos que se presentan en este artículo se construyeron a partir de una investigación etnográfica, específicamente un estudio de caso realizado bajo el alero de la narración que aporta a la premisa de la "reivindicación del sujeto personal en las ciencias sociales". Así, nos referimos a una narración que también es acción, es decir, "experiencia hermenéutica" (Gadamer, 1993, p. 104).

Por otra parte, desde la perspectiva de Ricoeur, el acto de relatar considera la participación de metáforas/metonimias en términos de predicación arbitraria, en otras palabras, significaría "llevar al lenguaje una experiencia, un modo de vivir y de estar en el mundo que le precede y pide ser dicho" (2000, p. 494).

En consecuencia, en nuestra investigación el corpus está compuesto por el relato de los miembros de una familia que habita un sector de la comuna de Paine, ubicada en la zona central de Chile, a $45 \mathrm{~km}$ de Santiago. Este grupo familiar está conformado por cuatro generaciones, totalizando 15 miembros cuyas edades fluctúan entre los 6 y 70 años.

En la práctica concreta de la indagación, se consideró la utilización de una amplia variedad de procedimientos (observación participante; grabación en audio y vídeo; foto/voz, recuperación de fotografías; mapas mentales; DAFO con actores; entrevistas formales e informales; línea de tiempo y discusión grupal), siendo la articulación y conexión entre estos una constante en la forma de hacer investigación.

Desde aquí, la perspectiva de análisis obedeció a la búsqueda de un discurso/praxis hermenéutico, en coherencia con la posición que privilegia una visión polifónica e integral, una acción discursiva que es "una práctica social en sí misma" (Iñíguez, 2006, p. 124) y que se basó en una adaptación libre de la ya flexible propuesta de Jesús Ibáñez. En este marco, se realizó un análisis estructurado en torno a tres fases que integran una serie de técnicas. Primer Nivel: Ethos nuclear, que alude a las propiedades internas del discurso, centrado en la verosimilitud referencial, lógica, poética y tópica. Segundo Nivel Autónomo: Agrupamos bajo las mismas categorías aquellos discursos en que acuden elementos similares, trabajando, además, con el elemento externo. Tercer Nivel total: Recuperación de la unidad del material discursivo (Ibáñez, 1985; Jociles, 2005). 


\section{RESULTADOS Y ANÁLISIS}

Dar cuenta de las preocupaciones existenciales representadas en el discurso narrativo por medio de tropos, responde a la idea de concebir que en la existencia habita la irreemplazable contingencia del origen en su incondicionado devenir.

Así, la existencia no es posible sin el ser-ahí y sus modos, pues "estos modos son indispensables para que ésta llegue a manifestarse y se vuelva real" (Fink, 1995, p. 88). Desde aquí, el ser ahí se plasma en lo que nombra y en lo nombrado se esclarece; por tanto, resulta comprensible que se anuncie mediante tropos.

Postulamos que los tropos (metáforas/metonimias) serían la punta del iceberg de una serie de concepciones co-formadas en diversas y singulares determinaciones, que habrían estado históricamente actuando y que aflorarían en esta forma de discursos. De esta manera, insistimos que los tropos son ilustraciones que intentan abrir debates, despertar inquietudes y disparar líneas de reflexión y argumentación.

Guiones, rostros o tropos, o como deseemos denominarlos, constituyen la forma en que nos ex-ponemos al mundo, ya sea desde lo sagrado de nuestra pertenecía al todo, desde la acción o desde el sacrificio; conformando tentativas del ser humano de abrir lo otro, en todas sus formas y contenidos y, a partir de ello, abrir también su ser de modo diferenciado y contingente.

La forma que tomará nuestro recorrido considera exponer las anunciaciones del tropo pasar a llevar desde las figuras vitales (etapas de vida, roles, etc.) que el ser experimenta, presuponiendo que ellas representan más que un asunto puramente biológico, es decir, una condición externa contingente, determinada social y culturalmente.

Suponemos que los modos existenciales que se constituyen en cada una de estas fragmentaciones o determinaciones evidencian continuidades y discontinuidades.

Estar ahí en el modo del pasar a llevar

Pasar a llevar representa una metáfora/metonimia doble, en términos espaciales y temporales. Constituye una voz que se enuncia como un dato incuestionable, como una expresión plenamente política, subyaciendo en ella una organización ideológica que da cuenta de las transformaciones en las relaciones de producción entre los seres humanos. 
Una de las proyecciones que nos propone este tropo es pensar la existencia en términos de transporte, en especial la idea de cargar un peso. Por lo tanto, pasar a llevar podría significar que en el tránsito de un lugar a otro se lleva una carga, la propia y tal vez la de otros, esta última puede ser por voluntad o simplemente porque no se considera a ese otro y se le transporta como carga. Entonces el conflicto que se origina nace de la forma en que se transita por este mundo, reduciéndose a: devenir carga o devenir cargador.

En segundo lugar, surgen las asociaciones frente al fenómeno de la desconsideración, que nos remite a la idea de falta de respeto o atención hacia un ser, muy relacionado con las proyecciones: avasallar, ultrajar, no tomar en cuenta, desconsiderar, ignorar, imponer, coaccionar, manipular. Presumiblemente, pasar a llevar sería una expresión que condensa la concepción que la existencia es un intento de ser considerado por los otros o una oportunidad de no considerar a los otros, o ambas situaciones.

En tercer lugar, más asociado a la anterior proyección pero con otro matiz, hallamos el término "excederse", pasar a otro lugar, dando a entender que cada ser transita dentro de ciertos límites pero algunos pueden traspasarlos, invalidando al que transita por este lugar.

Ilustrativamente, revisaremos algunos fragmentos que dan cuenta de las diversas configuraciones del tropo:

a) Fragmento 1, abuela': Pasar a llevar - dar gusto uno:

Rosa: Hace unos 15 años que cambio. Cambio porque está viejo, por eso, porque ya no... hablando en claro, como también era medio picao de la araña y ahora como no pasa na y ahí se empezó a componer, ya cuando trabajaba íbamos a comprar las cosas a Buin y todo y desde ahí se ha compuesto un poco más. Ahora está mejor que antes, da plata para la casa y todo.

Entrevistadora: ¿Pensó en separarse de él?

Rosa: Ahhhhh, sí, pero no lo hice nunca, nunca y ¿sabe por qué?, porque cuando estaban mis chiquillos chicos lo soportaba por mis chiquillos, porque decía yo, ¿a dónde va a dar gusto uno?, aunque sea como sea el hombre, aunque sea un palo, ya hay un respeto y estando sola uno, cualquiera la pasa a llevar y los chiquillos van a sufrir más, así que por eso.

Desde este fragmento se desvela la premisa de que el ser ahí implica pasar, un pasar restringido a la determinación de dar gusto, es decir, un

\footnotetext{
${ }^{1}$ Entrevista informal durante el trabajo de campo.
} 
pasar que tiene que acomodarse a ciertas formas pre-establecidas, a ciertas expectativas de los otros que habitan el mundo. Un pasar que se haría con el salvoconducto de la compañía de un hombre, aunque sea un palo.

Podemos observar que las estrategias argumentativas puestas en juego en este fragmento tienen su fuerza persuasiva en la interacción de las expresiones: dar gusto uno y pasar a llevar. Así, el argumento de pasar a llevar solo es una trama subyacente a la superioridad y prestigio del razonamiento dar gusto. En arreglo a las circunstancias, estas proposiciones no parecen incompatibles, pues ambas se asocian a un proceso del devenir con otros en unas condiciones determinadas. Condiciones que se resumen en dar gusto, remitiendo a un transitar sin manifestarse. Bien se podría expresar analógicamente como un devenir en que no pasen a llevar, da gusto a sí mismo y a los otros.

Extendiendo esta analogía, podemos observar un enlace de sucesión y un nexo causal: para dar gusto no te pueden pasar a llevar y la única manera es estar en compañía de un hombre. Este enlace tiene sin duda el efecto de aproximar de modo reciproco: dar gusto y pasar a llevar. De esta forma, al plantearse la posibilidad de separarse de su marido, los argumentos de dar gusto y por tanto, no pasar a llevar, actúan como explicación de su no separación.

$\mathrm{Al}$ seguir atendiendo los matices dialógicos que se observan en el enunciado completo ¿̇a donde va a dar gusto uno?, desde la perspectiva bajtiniana (2002) podemos observar una distinción entre el sujeto de la enunciación y el sujeto del enunciado, además de una relación entre ellos. Es así que tenemos un enunciado que pertenece al sujeto discursivo voy ¿Qué hablante discursivo se escucha en el enunciado? Un ser al que le importa su existencia y asume la obligación de llevar la carga que le ha sido arrojada: los hijos. Desde esta perspectiva, el enunciado dar gusto estaría ligado a una dimensión temporal y espacial, resultando además un portador ideológico. En otras palabras, dar gusto sería la condición por excelencia del servilismo y la no manifestación.

b) Fragmento 2, abuelo²: Si me pasan a llevar, yo me quedo callado

Juan: Yo no aguanto que me pasen a llevar, pero si me pasan a llevar por casualidad, yo podría ir mochito (directo) y lo voy a agarrar, capaz que el otro me pegue y me deje peor, entonces yo creo que eso no debe ser

\footnotetext{
${ }^{2}$ Grupo de discusión conformado por la generación de los padres y abuelos.
} 
así. Si a mí me pasan a llevar, yo me quedo callado, no le meto boche (escándalo) al que me paso a llevar, porque si no, yo me voy con las groserías y los golpes.

Entrevistadora: Pero, ¿qué es pasar a llevar?

Juan: Que te pasen llevar es que te traten mal, que le manden un empujón a usted, que le pegue un palmetazo a usted y a lo mejor, usted no se va a quedar, va a ir y él le va a pegar otro palmetazo, yo pienso así... sé que no todos pensamos lo mismo.

Los elementos que se proyectan desde el foro al tema están más asociados al padecer y experimentar la desconsideración. Desde esta perspectiva, pareciera que Juan basa sus acciones vitales en una serie de conocimientos elementales, prácticos y funcionales, que le permiten sobrevivir eficientemente; consentimos que es una interpretación anquilosada en esquemas causales, donde las condiciones y necesidades contextuales actúan como determinantes.

Si nos posicionamos en la perspectiva de un ser que asume la responsabilidad de su existencia, podemos vislumbrar otras voces interpretativas, entre ellas, una que des-vela un elemento proyectado desde el foro: prescindir de algo deliberadamente. La condición "deliberadamente" se mostraría en la expresión si me pasan a llevar por casualidad, pues se observa la tendencia a naturalizar la transgresión, transformando el devenir en un silente permiso de ser transgredido en su ser ahí. Quizá, se asume tal posición al considerar que, a fin de cuentas, este es solo un mundo de paso a aquel mundo "donde se va al descanso eterno", a ese mundo al "que se va el pobre".

Dicha transgresión podría no ser tal, ya que lo que importa es pasar de este mundo al otro. Es más, podemos presumir que si se es llevado o transgredido en la condición de pasar, existirían mayores posibilidades que "corte al cielo, pues todos los pobres llegan allí".

En consecuencia, hacemos referencia a un argumento que se asienta en el lugar de la cantidad, en que se prefiere la vida eterna de descanso frente a la vida terrestre de peón. Razonamiento que se legitima si ponemos atención a: me quedo callado, no le meto boche al que me paso a llevar, porque si no, yo me voy con las groserías y los golpes. Desde aquí pareciera que a él le importa su carga, no obstante, no desea la sobrecarga que se originaría por la lucha ya pérdida de hacerse respetar.

\footnotetext{
${ }^{3}$ Enunciaciones que se extraen de otros fragmentos discursivos elaborados por Juan.
} 
Ciertamente, buscamos llamar la atención del lector de modo que las expresiones de Juan susciten emociones, pues su verosimilitud poética realmente nos conmueve: golpes, groserías, empujones, etc., todos elementos del mundo cotidiano y sacrificios que intentan concretar lo abstracto de ser prescindibles.

Un ser arrojado a este mundo, entregado a los pasares y cargas ajenas, donde cada existencia se constituye en pasar llevando la propia carga al ritmo de los otros, puesto que esta así es asumida, debido a que lo importante es llegar a ese mundo al que llegan los pobres, los desconsiderados.

Con esta analogía observamos la asimetría entre la relación pasar y llevar. Una relación jerárquica que valora el pasar como principio rector del devenir, encerrando una premisa ideológica básica, que la condición de laborante no le permite la posibilidad de pasar a llevar a otros, ni tampoco de aumentar la carga que debe llevar. La labor de su cuerpo, con la que pasa por este mundo, es ya suficiente como para arriesgarse a luchar para que otros lleven su propia carga. Al final pareciera que él no busca ser visible o estar con otros en el espacio público.

Aunque esté presente la idea, a lo mejor usted no se va a quedar, va a ir, desde la perspectiva bajtiana Juan deja claro que su marco de conversación es dialógico. Él enuncia la existencia de dos o más logos, cada uno con sus propios valores, voliciones y posicionamientos. A partir de aquí, se observa una heteroglosia, la de él, los otros y la de la investigadora como auditorio. En su discurso topa con otros, por lo que su devenir se dialogiza en una frontera llena de tensiones. El yo y el usted. El usted que se resiste a ser llevado y el yo que aguanta.

Consideramos relevante intentar interpretar cuáles serían las premisas que permiten a Juan fundamentar las jerarquías que justifican sus elecciones. Sin duda, se trataría de los lugares de accidente (Vera Cruz, 1989, p. 45). Así, se observa que tiene más valor para Juan lo inmóvil que lo móvil, entendido esto como una sucesión de hechos, en otras palabras, la inmutabilidad al pasar por este mundo. Al parecer, él transita a través de la atenuación más que de la exaltación.

En síntesis, Juan se serviría de estas premisas para mostrar que prefiere la vida eterna a la vida en este mundo, al que fue arrojado como peón. El labrador es el elegido para ir al cielo, por tanto, su moral es la de un superhombre y de ahí adquiere todo su incentivo y su prestigio. 


\section{c) Fragmento 3, tía ${ }^{4}$ : Pasar a llevar y protección}

Ana: Es como protegerse, que nadie los traten mal.

Entrevistadora: ¿Sus hijos y sobrinos están preocupados de que no los pasen a llevar?

Ana: Siempre le hemos dichos a los hijos, fíjate que no te pasen a llevar, que nadie te pase a llevar, siempre uno le dice que nadie te pase a llevar. Los papas no quieren que los humillen como a ellos.

De esta forma, ella remitiría a la propiedad proyectada de pasar, como padecer, que desde su etimología significa sufrir, soportar, y que considerando el contexto discursivo se acercaría al nombre griego (pathos) que expresa el dramatismo trágico de experimentar; como también la propiedad de no ser considerado o no contar con la atención de los otros, es decir, no estar presente. Analógicamente podemos inferir que se transita por este mundo desde una actitud de guarecerse, parapetarse y, en especial, resguardar un bien en una existencia en que el ahí o la vida se hace, en el descubrimiento que el propio ahí es vulnerable y que resiste escasamente la erosión del transitar.

En otras palabras, se anunciaría la premisa que el ser tiene una débil red que lo sujeta, por lo cual cabe la posibilidad de que los otros consideraren que no tiene la capacidad de hacer su vida, por lo que sería legítimo pasarlo a llevar, en el sentido de llevarlo como carga o colonizarlo, "que sea lo mismo", de acuerdo a lo planteado por Dussel (1994).

En segundo lugar, desde el tópico de lo probable, experimentar que te pasen a llevar es casi insoslayable en la condición de peones, justificando la acción de protegerse y defenderse en la medida en que se intenta pasar a otro mundo. La protección surge frente a la realidad que la condición de laborante te hace débil, peligrando el propósito del ser ahí: hacer y pasar.

Si nos detenemos en el concepto humillar, que desde su origen en latín significa hacer que un ser se postre, se arrastre por el suelo u obligarlo a reconocer su bajeza, este claramente tendría un origen metafórico/metonímico que lo situaría en el grupo de los tropos orientacionales (Lakoff \& Johnson, 1986), surgiendo de la experimentación del cuerpo, al suscribirlo a la condición de labradores, de un hacer en contacto con la tierra, man-

\footnotetext{
${ }^{4}$ Fragmento del grupo de discusión de la generación de padres y abuelos.
} 
teniendo generalmente la posición de agachados o a ras de piso, haciendo patente la asociación.

No obstante, lo inquietante acontece al extender esta actividad al ámbito personal y sobre todo público, es decir, desde la posición del que humilla. La pretensión lógica sería que la condición del postrado se mantuviera en todos los espacios.

Desde la perspectiva levisiana, la posición de encorvado impediría mostrarse, puesto que su rostro no estaría frente al otro, sino que estaría mirando el piso. En el acto de humillar no existiría una acogida del rostro, en tanto fuerza ética ejercida sobre alguien, como poder moral que cristaliza un yo. Al estar encorvado, el rostro del otro no se considera como potencia expresiva y no puede presentarse a sí mismo (Levinas, 1991).

d) Fragmento 4, hijo5: Pasar a llevar-saber

Juanjo: Obviamente la gente de repente pasa a llevar al que no sabe, yo creo que es un tema de sociedad, el tema que siempre van a tratar de aprovecharse de las cosas, obviamente la gente siempre se va a aprovecharse del que sabe menos.

Entrevistadora: ¿Crees que la gente de campo sabe menos?

Juanjo: En algunos aspectos sí.

Entrevistadora: ¿¿n qué aspectos?

Juanjo: Yo creo que saben menos de... (silencio) no saben en cuanto a tecnología, risas... porque ellos no necesitan más. Creo que va en el trato con las personas, obviamente, por eso mismo mucha gente los pasa a llevar... por lo mismo. Mi abuelo tiene o tuvo el problema que fue a trabajar un día y el viejo que los contrato no les pago y mi abuelo por su forma de ser, ha ido, ido, ido y no le ha pagado, creo que eso es pasarlo a llevar, por cómo es él, piensan que todos los que trabajan en el campo y no saben... pueden hacer lo que quieran con ellos.

Entrevistadora: ¿Pero ellos saben más de otras cosas?

Juanjo: Si, ellos saben mucho más de la vida.

Entrevistadora: ¿Por la edad o por la vida que han tenido?

Juanjo: Por la vida que han tenido. No sé, mi tío tampoco tuvo estudios, pero sé que no lo hacen tonto en ninguna parte, el trabajo de campo él lo sabe y no se deja pasar a llevar por nadie. No habrá terminado el colegio, pero para el trabajo que él hace, él sabe... en ese sentido no se deja pasar a llevar.

\footnotetext{
${ }^{5}$ Entrevista durante trabajo de campo.
} 
La figura pasar a llevar en este fragmento discursivo nos centra en la relación pasar a llevar y saber. No obstante, para posibilitar un análisis polifónico es importante identificar los lugares en que se posiciona Juanjo para formular sus razonamientos.

En primer término, podemos vislumbrar el tópico de la división u oposición, infiriendo que la esencia del humano se constituye por su anhelo de saber, existiendo los que saben y los que no saben; dando origen a una división contingente, que también remitiría a la división de los actos y las personas.

Juanjo formula una explicación con características similares a una argumentación cuasi lógica, ya que su presentación es comparable a razonamientos formales, que al adaptarse al esquema que nos brinda Aristóteles, se expresaría de la siguiente forma: los que poseen la ciencia de lo universal, es decir, cuyo saber no está subordinado a lo particular, saben más y, por tanto, dictan las leyes por las que se rigen los que no saben; consecuentemente, es lógico que se pase a llevar al que no sabe, pues el menos sabio está subordinado al más sabio; el primero debe obedecer, el segundo dicta las leyes.

Se entiende que el hombre sabio, al conocer todo de modo general, sin extenderse a lo individual, elabore leyes que no conciban lo particular, situación que es valorada por los no sabios como pasar a llevar. Por lo tanto, el argumento esgrimido es extraído probablemente del argumento de autoridad.

La exposición de la situación vivida por su abuelo tiene como propósito reforzar la adhesión a la regla conocida, a los que saben menos los pasan a llevar. Por otra parte, el ejemplo del tío solo logra dar cierta variabilidad a las posibles aplicaciones de la misma regla. El argumento pasar a llevar al que no sabe se ve reforzado. Juanjo es consistente desde el lugar donde extrae sus argumentaciones, ya que la división y oposición tendrían como efecto la ordenación, resaltando la inconmensurabilidad entre los distintos saberes y su jerarquización.

e) Fragmento 5, hijo ${ }^{6}$ : No le aguanté que me pasara a llevar

Pato: Igual los jefes me tienen ahí no más, tratan de no buscarme... de no buscarme el odio, porque ya saben cómo soy. Un año me puse a

\footnotetext{
${ }^{6}$ Fragmento de una grabación de una cena familiar.
} 
pelear con uno, que era trabajador como nosotros, pero esa vez lo mandaron como jefe, no le aguante que me pasara a llevar, le dije, tú soy un trabajador igual que yo. Me dijo: no, yo estoy a cargo de toda la cuestión. Está bien que el patrón te haya dejado a cargo, pero soy un trabajador igual que nosotros, entonces también tenís que hacer las cosas que estamos haciendo y me dijo no. Entonces deje la embarrada y fui a hablar con el jefe y le dije paso esto, esto y esto, le dije todo, dije todo lo que había pasado: me puse a pelear porque me pasó a llevar; yo le dije que era un trabajador igual que nosotros, que está bien que usted lo haya dejado a cargo, pero no era para que estuviera sentado todo el día.

La perspectiva que nos brinda Pato se asienta presumiblemente en la relación que se establece entre me tienen ahí no más y no le aguante que me pasara a llevar. Al segmentar los tropos, consideramos relevante detenernos en la expresión ahí no más, que tendría varios significados, entre ellos podemos distinguir dos que guardan cierta coherencia con el contexto discursivo y extradiscursivo.

El primero implicaría la demanda de poner un alto a ciertos actos o circunstancias, llevándonos a presumir que su condición de temporero agrícola no le impide poner un límite a su posición de subordinado. El segundo guarda mayor relación con el modo estructurante la vida es aquí, es decir, el ser ahí. Un ahí en el cual se concreta un proyecto vital que se origina en poner de manifiesto un ser que se hace cargo de sí y de sus posibilidades.

Desde la perspectiva heideggeriana se haría mención al proceso de ocuparse de su arrojo, de su caída, pero especialmente de su necesidad de encontrarse a sí mismo, preguntándose por lo que puede llegar a ser en este mundo (Heidegger, 1974, p. 70). Considerando esta última acepción, Pato nos anunciaría un ser ahí que se ocupa, pues intenta persuadirnos que pone límites, frenos que posibilitan su estar ahí en este mundo. Límites que lo salvan de que lo pasen a llevar.

Podemos presumir, entonces, que Pato recurre al argumento de la regla de justicia, aludiendo a una reducción parcial de los elementos en cuestión, en este caso a la identidad de los que debían realizar un trabajo.

Se desprende que, a diferencia de los argumentos esgrimidos por otros miembros de la familia, él no asocia en forma directa el pasar a llevar con la humillación o con la invisibilidad. Él la asocia más bien con la justicia, con el no abuso, enunciándose de la siguiente manera: si cada uno tiene ya su carga, no es justo que otros le quieran poner más peso, "abuso que con merito debe ser condenado" (Vera Cruz, 1989, p. 45). 


\section{CONCLUSIONES}

Desde la premisa que nuestros participantes viven y conviven en una cultura determinada, nos preguntamos ¿cuáles serían los referentes culturales del modo existencial: pasar a llevar? La respuesta tentativa es una configuración sociocultural e histórica centrada en relaciones de dominación, sometimiento y competencia, con sus respectivas consecuencias de aislamiento e invisibilidad para muchas comunidades en todo el mundo. Podemos pensar que esta familia ha heredado y re-crea modos existenciales que fueron co-formando en un tipo de relación propia de la organización de las haciendas. Un sistema que buscaba someter al otro, haciendo uso de innumerables herramientas, dicho sea de paso, muy eficientes.

La situación de los gañanes en Chile, especialmente en la zona central, llevó a concebir la existencia como una permanente lucha, para situarse a sí mismo como un ser ahí, considerado y legitimado, lo cual originó, consecuentemente, concepciones de un modo existencial de resguardo y protección. Los gañanes, que no contaban con la "protección" del sistema hacendal porque eran vagabundos en busca de trabajo, necesitaban guarecerse para no ser sorprendidos en el camino y cogidos a la fuerza para ejercer labores de las cuales habían escapado (Salazar, 1989).

Desde aquí, parece válida la afirmación que el ser ahí "se transforma de una manera u otra, según el espacio relacional humano en el que le toca vivir, esto quiere decir que el ser aprende a hacer las distinciones y correlaciones propias de ese espacio relacional" (Maturana, 2006, p. 49).

Presumimos que para los miembros de esta familia (cada uno con sus matices) existir en este mundo y relacionarse con lo Otro en la forma de pasar a llevar, se haría en el modo de cuidado, de atención al hacer la vida, por cuanto no solo se concibe que la vida se hace, sino que además se hace vigilando al otro para que no te pase a llevar. Parece ser un modo de existir siempre alerta, que presumiblemente estaría en una constante búsqueda de herramientas que lo ayuden a defenderse del otro, quizás, levantando fortalezas que le permitan hacer su vida.

No obstante, el pasar a llevar es un modo de ser ahí plenamente activo. El ser ahí se vivencia como un ser que debe hacer la vida a resguardo, un ser que asume que está entre las cosas del mundo, entre los seres del mundo, caminando entre ellos de una manera interesada, implicada, cuidando que las cosas y los seres atiendan a su presencia. Así, este ser que existe en el modo pasar a llevar, crea y re-crea lo único que constituye su "verdadera" 
relación con el mundo. Un modo de existir que "sabe de su caer y desaparecer, que capta el viento voraz, el viento silbante de la transitoriedad" (Fink, 1995, p. 114).

Proponemos que pasar a llevar constituye el espacio humano del mundo que conciben los miembros de esta familia. Modo que se re-crearía con fricciones entre una generación y otra, observándose continuidades y discontinuidades. De esta manera, apreciamos por un lado al abuelo, que otorga mayor relevancia al hacer la vida no despilfarrando recursos, ya precarios, en una defensa del ser ahí; y, por otro lado, a algunos de sus nietos que subordinarían el hacer la vida a la necesidad de ser considerados como legítimos hacedores.

Otro elemento que se desprende de este modo del ser, es el reflejo de una particular réplica del Otro. Es decir, el otro se muestra aquí como un ser que busca arrebatarles la posibilidad de hacer la vida, transformándose en un momento determinado en un Otro que los definió como prescindibles. Al parecer, esta condición de prescindibilidad quedó grabada en el imaginario de las primeras generaciones y se ha re-creado en las siguientes.

\section{REFERENCIAS}

Argueta, A. (2011). El diálogo de saberes, una utopía realista. En: Saberes colectivos y diálogo de saberes en México. Cuernavaca: UNAM, CRIM: Puebla. Universidad Iberoamericana.

Bajtín, M. (2002). Estética de la creación verbal. Buenos Aires: Siglo XXI.

Contreras, S. (2013). Esbozo de una pedagogía vulnerable: narrativas y retóricas locales. Tesis doctoral. Madrid: Universidad Complutense de Madrid.

Contreras Salinas, S.; Ramírez Pavelic, M. (2013). "Avanzando en el diálogo de saberes". Arbor, 189(759):a011. doi: http://dx.doi.org/10.3989/ arbor.2013.759n1010.

De Sousa Santos, B. (2003). Crítica de la razón indolente. Contra el desperdicio de la experiencia. Volumen 1. Bilbao: Editorial Descleé.

Dussel, E. (1994). El encubrimiento del otro. Hacia el origen del mito de la modernidad. México: Editorial Plural.

Fink, E. (1995). Fenómenos fundamentales de la existencia humana. Bérlin: Karl Alber.

Foucault, M. (1968). Las palabras y las cosas. Una arqueología de las ciencias humanas. Buenos Aires: Siglo XXI.

Gadamer, H. G. (1993). Verdad y método I. Salamanca: Ediciones Sígueme.

Heidegger, M. (1974). Ser y tiempo. Ciudad de México: Fondo de Cultura Económica. 
Ibáñez, J. (1985). “Análisis sociológico de textos o discursos". Revista Internacional de Sociología, 43(1), 119-160.

Iñíguez, L. (2006). El análisis del discurso en las ciencias sociales: variedades, tradiciones y prácticas. En L. Iñíguez, Análisis de discurso. Manual para las ciencias sociales (pp. 89-128). Barcelona: Editorial UOC.

Jociles, M. (2005). "El análisis del discurso: de cómo utilizar la propuesta de Jesús Ibáñez desde la antropología social”. Revista de Antropología Avá, 7, 147-169.

Lakoff, G., \& Johnson, M. (1986). Metáforas de la vida cotidiana. Madrid: Ediciones Cátedra.

Levinas, E. (1991). Ética e infinito. España: La balsa de la Medusa, Colección dirigida por Valeriano Bozal, Editorial Antonio Machado.

Maturana, H. (2006). "Educación desde la matriz biológica de la existencia humana. Biología del conocer y biología del amar”. En E. Carrasco, B. Negrón, \& A. Astorga (Eds.), Sentidos de la educación y la cultura: cultivar la humanidad (pp. 45-57). Santiago de Chile: Lom.

Mignolo, W. (2010). Desobediciencia epistémica: Retórica de la modernidad, lógica de la colonialidad y gramática de la descolonialidad. Buenos Aires: Colección Razón Política, Ediciones del Signo.

Ricoeur, P. (2000). "Narratividad, fenomenología y hermenéutica”. Análisis: Cuadernos de comunicación y cultura, 25, 189-207.

Salazar, G. (1989). Labradores, peones y proletariados. Santiago de Chile: Ediciones Sur.

Tadeu da Silva, T. (1999). Documentos de identidades. Uma introduçao às teorìas do curriculo. Belo Horizonte: Editorial Autentica.

Vera Cruz, F. A. (1989). Tratado de los tópicos dialécticos. Ciudad de México: Universidad Nacional Autónoma de México. 